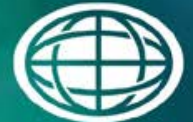

Savannah River

National Laboratory

OPERATED BY SAVANNAH RIVER NUCLEAR SOLUTIONS

Reductions without Regret: Avoiding

Wrong Turns, Roach Motels, and Box

Canyons

11 September 2013

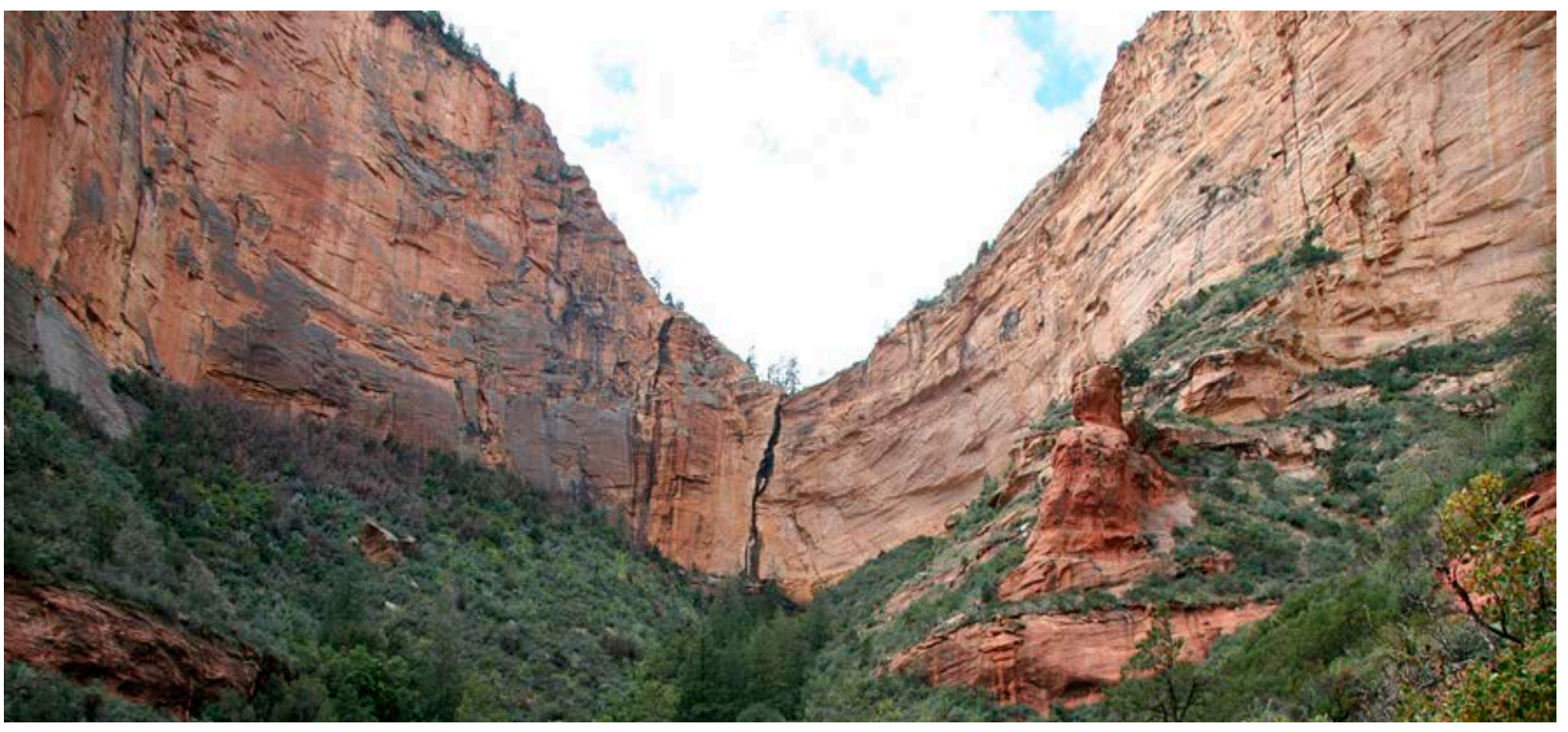

John A. Swegle

Douglas J. Tincher 
The analysis contained herein is that of the authors and does not reflect the views or positions of the Savannah River National Laboratory, the National Nuclear Security Administration, or the U.S. Department of Energy.

Savannah River National Laboratory

Aiken, SC 29808

John A. Swegle, 735-11A, Room 113, (803)725-3515

Douglas J. Tincher, 735A, Room B102, (803)725-4167 


\title{
Reductions without Regret: Wrong Turns, Roach Motels, and Box Canyons
}

\author{
John A. Swegle and Douglas J. Tincher \\ Savannah River National Laboratory
}

This is the third of three papers (in addition to an introductory summary) aimed at providing a framework for evaluating future reductions or modifications of the U.S. nuclear force, first by considering previous instances in which nuclear-force capabilities were eliminated; second by looking forward into at least the foreseeable future at the features of global and regional deterrence (recognizing that new weapon systems currently projected will have expected lifetimes stretching beyond our ability to predict the future); and third by providing examples of past or possible undesirable outcomes in the shaping of the future nuclear force, as well as some closing thoughts for the future.

In this paper, we provide one example each of our judgments on what constitutes a box canyon, a roach motel, and a wrong turn:

- Wrong Turn: The Reliable Replacement Warhead

- Roach Motel: SRAM T vs the B61

- A Possible Box Canyon: A Low-Yield Version of the W76 SLBM Warhead

Recognizing that new nuclear missions or weapons are not demanded by current circumstances - a development path that yields future capabilities similar to those of today, which are adequate if not always ideal, and a broader national-security strategy that supports nonproliferation and arms control by reducing the role for, and numbers, of nuclear weapons - we briefly consider alternate, less desirable futures, and their possible effect on the complex problem of regional deterrence. In this regard, we discuss the issues posed by, and possible responses to, three example regional deterrence challenges: in-country defensive use of nuclear weapons by an adversary; reassurance of U.S. allies with limited strategic depth threatened by an emergent nuclear power; and extraterritorial, non-strategic offensive use of nuclear weapons by an adversary in support of limited military objectives against a U.S. ally.

\section{Avoiding Wrong Turns, Roach Motels, and Box Canyons In the Path Forward}

In facing the dual processes of modernization and force reductions, a particular concern is that "box canyons," "roach motels," and "wrong turns" be avoided (see the text box on the following page for definitions). Each is problematic, with differing degrees of reversibility. In this paper, we consider the possibilities for losing, or compromising, key capabilities of the U.S. nuclear force in the face of modernization and reductions. In three earlier papers (including our introductory summary), we first reviewed the stated goals for reduction, driving forces, and long-term goals; second, we adopted an historical perspective, considering capabilities that were eliminated in past force reductions; and third, we attempted to define the needed capabilities looking forward in the 


\section{Definitions}

Roach Motels of Reduction: Dead ends in force development that are irreversible due to certain combinations of factors.

\section{Box Canyons in the Valley of Disarmament:} Courses of action resulting in undesirable force compositions or structures that can be reversed, albeit at the expense of "going back the way one came in."

\section{Wrong Turns on the Road to the Future:}

Courses of action creating undesirable force compositions or structures that can be undone by a change of direction. context of the current framework for force modernization and the current picture of the evolving challenges of deterrence and assurance.

Currently, the prognosis is for the U.S. nuclear force to continue on a qualitatively similar path to that of today, with marginal or evolutionary changes in capability. To be sure, planned reductions in the number of tubes on $\operatorname{SSBN}(\mathrm{X})$, or mounting single warheads on Minuteman III or its possible replacement, both make downward scaling more straightforward from a hardware standpoint. Indeed, with the reduced warhead loading, it also provides some headroom for uploading in a pinch. Absent a

dramatic change in international relations at the global or regional level - and Iran remains a wild card in the Middle East - or a revolutionary increase in capability by another nation, there is little or no pressure to modify the balance of capabilities or try to recover a capability eliminated by previous decisions.

Nevertheless, it is prudent to have in mind plans to recover options as needed, or to attempt to preserve future options in ways that will be both politically supportable and manageable in terms of their escalatory impact internationally. In the three sections following, we briefly consider historical examples of the box canyons, roach motels, and wrong turns of the title, as well as the lessons that might be gained for the future. We then close the paper with a consideration of possible futures, less likely than those presented today, and additional options for changed expectations.

\section{A Wrong Turn: The Reliable Replacement Warhead}

Congressional funding for the Reliable Replacement Warhead first appeared in the Fiscal Year 2005 (FY05) federal budget, with the simple explanation that it was to be an effort "to improve the reliability, longevity, and certifiability of existing weapons and their components." ${ }^{1}$ However, funding was zeroed in the FY09 budget, and in March 2009, the program was formally cancelled. In that short period of time, a design competition between the nuclear-weapons design laboratories was held and decided in favor of a team from the Lawrence Livermore National Laboratory (LLNL) and Sandia National Laboratories (SNL). Congress requested and received supporting studies from the JASON advisory group, ${ }^{2,3}$ the Defense Science Board (DSB), ${ }^{4}$ the American Association for the Advancement of Science (AAAS), ${ }^{5}$ the National Academy of Sciences, ${ }^{6}$ and a Congressional Commission on America's Strategic Posture. ${ }^{7}$ Additionally, the National Nuclear Security Administration (NNSA) produced reports on a future nuclear-weapons production complex, a 2005 study $^{8}$ from the Secretary of Energy's Advisory Board (SEAB), and a Congressionally-mandated Complex 2030 report, ${ }^{9}$ all to support production of a family of Reliable Replacement Warheads as well as Life Extension Programs of existing warheads, as necessary. 
The issues surrounding RRW - a type of warhead, the first of which, the WR-1, was being developed by the LLNL/SNL team - were both technical and political. Technical issues provided the initial motivation: RRW was to be the embodiment of a design and production philosophy intended as an alternative to the continued life extension of weapons designed and first deployed during the Cold War. The Defense Science Board had declared indefinite life extension and remanufacture to be "clearly not a sustainable approach." ${ }^{10}$ In the case of RRW, rather than optimizing warheads for maximum specific yield, the ratio of nuclear yield to warhead mass (measured in kilotons per kilogram), the basic strategy was to relax the requirement on specific yield and to capitalize on the greater mass allowable to increase design margins. ${ }^{*}$ Thus, the WR-1 was to have the yield of the W76, which was mounted in the Mk-4 reentry vehicle, but it was to be mounted in the larger Mk-5 RV of the W88. ${ }^{11}$ Derived from previously tested nuclear systems, ${ }^{12}$ the redesigned RRW warheads were to provide for:

- Ease of production, surveillance (observation of warhead properties and performance), maintenance, and dismantlement;

- Reduced need for nuclear testing;

- Utilization of readily available, non-hazardous materials in their construction;

- Control of safety (the prevention of unexpected detonation) and surety (a measure of confidence that the warhead will operate as planned under all circumstances);

- Reductions in life-cycle cost targets; and

- Modularity.

Whatever the intended advantages of RRW and specifically WR-1, the advantages of the new approach embodied by RRW were less clear-cut than intended in comparison to the practice of conducting Life Extension Programs (LEPs) of tested, known nuclear weapons. Barry Hannah, Chair of the RRW Project Officers Group, a key programmatic element, expressed his opinion to a member of the Congressional Research Service that the competing W76-1 LEP would meet the Navy's needs and provide for an increase in design margins in the process of compensating for known problems or expected uncertainties. ${ }^{13}$ Reviewers also noted that a new WR-1 would probably experience difficulties as a new system, with new production processes, that would take more time than expected to resolve. Substantial uncertainties about the ability of the existing NNSA nuclear weapons complex to produce new nuclear primaries, or pits, in the numbers required for a production run of WR-1 generated serious concern. When the FY08 budget eliminated funding for a Consolidated Plutonium Center to build new pits, while adding funding to explore the desirability of reusing existing pits in WR-1, the handwriting was on the wall.

Ultimately, the combination of political issues and unknown technical challenges were the undoing of RRW. The system was judged to be a "new" nuclear weapon, the introduction of which was regarded to be inconsistent with U.S. nonproliferation goals. Further, notwithstanding the fact that RRW was to be based on tested nuclear explosives and that its increased margins were intended to reduce the need for future nuclear testing, the fact that it was in some sense "untested," especially

\footnotetext{
"Margin" is defined broadly for a number of nuclear design metrics, or key "performance gates," as the difference between the normal, or design, operating point for a key parameter and the threshold value for operation. As an example (see the National Academy of Sciences report in the reference), if the identified parameter is the yield of a nuclear-weapon primary, and if the metric is yield of the secondary driven by the primary, the margin is the difference between the minimum primary yield required to achieve acceptable secondary yield, and the (larger) primary yield at which the primary has been designed to operate.
} 
in comparison with Cold War nuclear weapons, was regarded as a source of concern that it might create an impediment to ratification of the Comprehensive Test Ban Treaty (CTBT).

The Final Report of the Congressional Commission on the Strategic Posture of the United States provided a post mortem on the RRW, as well as a valuable lesson drawn from the experience: ${ }^{14}$

The two basic approaches to refurbishment and modernization are, in fact, not stark alternatives. Rather, they are options along a spectrum. That spectrum is defined at its two ends by the pure remanufacturing of existing warheads with existing components at one end and complete redesign and new production of all system components at the other. In between are various options to utilize existing components and design solutions as needed. Different warheads may lend themselves to different solutions along this spectrum.

$\cdots$

The commission recommends that Congress authorize NNSA to conduct a cost and feasibility study of incorporating enhanced safety, security, and reliability features in the second half of the planned W76 life extension program. This authorization should permit the design of specific components, including both pits and secondaries, as appropriate.

A year later, the 2010 Nuclear Posture Review Report assimilated this recommendation in large part. Looking forward over the coming 30 years, the report reached four conclusions about the future lifetime extension of existing nuclear weapons. In addition to pledges not to resume nuclear testing and to pursue ratification of the CTBT, these conclusions included the following: ${ }^{15}$

- $\quad$ The United States will not develop new nuclear warheads. Life Extension Programs (LEPs) will use only nuclear components based on previously tested designs, and will not support new military missions or provide for new military capabilities.

- The United States will study options for ensuring the safety, security, and reliability of nuclear warheads on a case-by-case basis, consistent with the congressionally mandated Stockpile Management Program. The full range of LEP approaches will be considered: refurbishment of existing warheads, reuse of nuclear components from different warheads, and replacement of nuclear components.

- In any decision to proceed to engineering development for warhead LEPs, the United States will give strong preference to options for refurbishment or reuse. Replacement of nuclear components would be undertaken only if critical Stockpile Management Program goals could not be otherwise met, and if specifically authorized by the President and approved by Congress.

Although the report did not mention movement to larger RVs, as was the case with RRW moving from the Mk-4 to the larger Mk-5, and while it stated a preference for refurbishment or reuse, the policy was moved to somewhere between the two technical endpoints called out in 2009 by the Congressional Commission. Now, nuclear components based on previously tested nuclear designs can be used as replacements in future Life Extension Programs.

The lesson of the RRW experience for the nuclear force was that new systems, even new systems with the military capabilities of previous systems, are problematic; however, modifications of existing systems, or options that can be portrayed as modifications of existing systems, are possible, subject to the proper approvals. In this sense, the RRW represented a wrong turn, a direction not pursued, but only a wrong turn.

Along these lines, in late 2012, the Nuclear Weapons Council adopted a new framework, still not fully finalized, for the maintenance of U.S. nuclear warheads, the so-called " $3+2$ " vision. ${ }^{16}$ This 
plan would include three "interoperable" ballistic missile warheads and two nuclear weapons to be delivered by aircraft, a gravity bomb and an air-launched cruise missile. The interoperable ballistic missile warheads would be carried by either the Mk-5 RV for the Trident-II SLBM or the Mk-21 RV for the Minuteman III ICBM. Both RVs could carry one of three nuclear-explosive packages (NEPs) integrated with non-nuclear systems that maximize the use of common and adaptable components. The first such interoperable warhead, the IW-1, is being developed with a design based on the melding of the existing W78 and W88-1 designs. Future warheads, the IW-2 and IW3 are projected at this time to be based on the life extension of the W87 and W88 (IW-2) and the W76-1 (IW-3). The air-delivered systems are currently expected to employ the B61-12 warhead for the gravity bomb, while a final decision for the cruise missile warhead has not yet been made.

According to a Pentagon official, ${ }^{17}$ the $3+2$ plan will result in reductions to (1) the number of warhead types, from seven to five; (2) the current heavy reliance on the W76; and (3) the overall stockpile size, because of the reduced requirement for non-deployed hedge warheads. It is hoped that the cost of warhead life extension and maintenance can be reduced, although it was admitted that DoD costs for the testing of the newly-loaded RVs could offset any savings. Finally, the plan is expected to help maintain nuclear design skills by presenting a greater challenge than a lifeextension program based on the refurbishment of existing warheads.

\section{An Historical Roach Motel: SRAM T vs the B61}

Development of new versions of the Short-Range Attack Missile, a supersonic missile originally designed to be carried by strategic bombers to aid in the penetration of enemy air defenses, was underway at the end of the Cold War: SRAM II (AGM-131A), to be carried by heavy bombers and armed with the W89 warhead, and SRAM T (see Figure 1), to be carried by the F-15E and armed with the W91 warhead. As recounted in a 1991 GAO report, serious problems, primarily with engine development, pushed SRAM II years behind schedule and caused costs to balloon, even following reductions in required performance criteria. ${ }^{18}$ This was the context in which SRAM II and SRAM T were cancelled as part of the PNIs of 1991 and $1992 .{ }^{19}$ Nevertheless, in announcing that cancellation, President Bush promised to retain "an effective air-delivered nuclear capability in

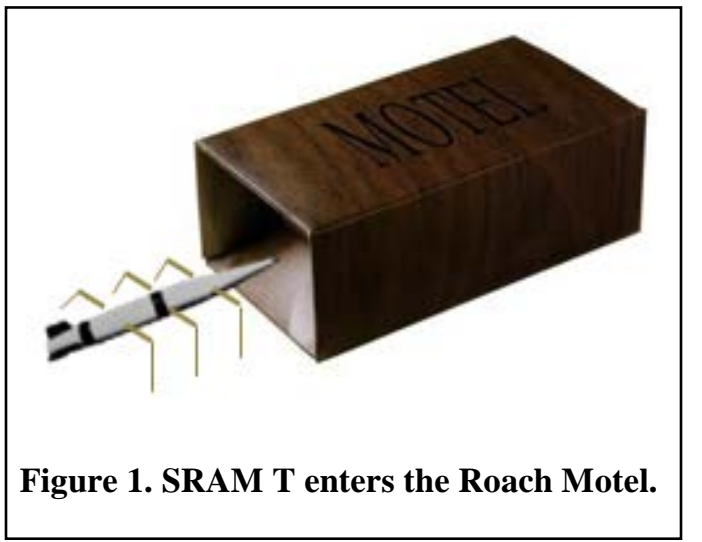
the delivery vehicle, would arguably be superior in military capability to a B61, which requires the delivering aircraft to penetrate essentially to within sight of the target. Further, as shown in Table 1, we see that except for the large differences in weight between B61 and SRAM II, the two have 
quite similar physical dimensions, possibly allowing the use of the same warhead for both and simplifying the task of modifying the delivery platform to carry a similar standoff missile.

Of course, the case study of RRW shows that military effectiveness is not the only factor affecting the desirability of developing a modern nuclear-armed short-range standoff missile (which we

\begin{tabular}{|c|c|c|c|}
\hline & SRAM II & ALCM & B61 \\
\hline Top Speed & Mach 2+ & High subsonic & -- \\
\hline Range (km ) & 400 & $2,400+$ & -- \\
\hline Length (m) & 3.18 & 6.3 & 3.56 \\
\hline Diameter (m) & 0.39 & 0.62 & 0.33 \\
\hline Mass (kg) & 900 & 1,430 & 320 \\
\hline
\end{tabular}
abbreviate N-SRSO) for tactical delivery. Indeed, circumstances have placed such a system in our so-called Roach Motel: it's gotten in, but under current circumstances, it is very unlikely to get out, for the following reasons:

- As we noted earlier, the current nuclear force appears to be up to the task of meeting U.S. deterrence requirements for the foreseeable future. In this case, development of a modern N-SRSO would probably be rejected as a "new," and likely superior, military capability even if it were deployed as a one-for-one replacement for B61. In this light, one could expect to see such a missile viewed as a threat to regional and strategic stability, a stumbling block for future arms control negotiations, and inconsistent with U.S. nonproliferation policy.

- B61 has become a visible symbol of the nuclear element of the NATO alliance, and the development of a new U.S. tactical nuclear weapon would likely stimulate considerable discussion within the alliance that would revive controversial issues raised at the 2010 NATO Lisbon Summit, and resolved in NATO's 2010 Strategic Concept.

- Substantial investment is being made in the Life Extension Program for B61, projected to be US\$10B as of July 2012, according to Senator Dianne Feinstein. ${ }^{20}$ It is unlikely that B61 would be replaced for some time, or that an additional tactical nuclear weapon would be developed at additional cost, except in the face of a significant new military requirement.

- Finally, an N-SRSO would have to offer a capability not provided by LRSO delivered by B-52H or a future LRS-B bomber.

Given the shorter range of the delivery aircraft, tactical N-SRSO would be most effective if based regionally; however, this would pose political and logistical challenges. Permanent basing in all but NATO countries presents political or regional stability difficulties. Temporary basing in time of elevated tensions would doubtless affect the level of tension, which becomes part of the calculus for doing so: Are the United States and its allies willing to pay the price for the elevated tensions? Is the signaling of moving an N-SRSO into the region actually a desirable outcome? One can see that temporary basing provides less flexibility for decision makers. Beyond the political-military issues, the logistics are demanding: it would be necessary to establish facilities with the necessary security and hardness to meet nuclear requirements.

Enhanced military capability alone would not justify development of an N-SRSO. Some combination of circumstances, most likely outside the Euro-Atlantic region, requiring a regional capability not provided by strategic ballistic missiles or LRSO that both deters adversaries and assures allies and partners would be the likely core motivation. 


\section{A Possible Box Canyon? A Low-Yield Version of the W76 SLBM Warhead}

Recently, ${ }^{21}$ Elbridge Colby argued that U.S. interests are best served by the inclusion of a nuclear capability that is "limited, discriminate, and evidently restrained." Considering the economic constraints, evaluating the alternatives among existing systems, and drawing on a suggestion by Ambassador Linton Brooks, he recommended that the best current option is a low-yield version of the W76 warhead carried on the Trident II SLBM. In his evaluation, the overflight issue for ICBMs is problematic, and the passage of time and development of defensive technologies has reduced the reliability of current delivery aircraft, B2 and T-DCA carrying gravity bombs and B-52 delivering ALCMs. Looking to the future, he recommended a defense-penetrating LRSO as likely a preferable option.

The point made by Colby was that effective nuclear deterrence that serves the interests of both the United States and its allies requires more than the single-minded pursuit of the goal of preventing all nuclear-weapons use. Rather, he wrote that such a limited strategy creates a vulnerability of its own and raises a question among U.S. allies about the resolve underpinning extended deterrence, a point notably made by German Chancellor Helmut Schmidt in a 1977 lecture. ${ }^{22}$ Colby argued that this creates a need, in effect, for additional rungs at the bottom of the escalation ladder to allow for the limited, discriminate demonstration that a conflict involves issues of sufficient national-security import that further pursuit could lead to a mutually disastrous nuclear exchange.

His desire for a de-escalatory demonstration capability mirrors in some important respects a lengthy public discussion conducted in the Russian military-theoretical literature during the 1990s, accompanied by shifts in Russian nuclear doctrine. ${ }^{23}$ Russian authors there generally favored, and fleshed out, a doctrine of limited use of nuclear weapons -drawing on Russia's greater breadth of non-strategic options as well as single-warhead ICBMs - in demonstration strikes aimed at preventing regional conflicts, nuclear or otherwise, from evolving to large-scale conflicts. Russian interest at that point was motivated more by the survival of the Russian state under conditions of acknowledged conventional inferiority, than by the credibility of any extended-deterrence commitments.

We would expand the discussion a bit to recognize evolving deterrence requirements that appear to differ at the global and regional levels. Returning to a point, the 2010 Nuclear Posture Review Report set dual goals of maintaining both strategic deterrence and stability on the one hand, and regional deterrence and assurance of allies and partners on the other. Looking forward from the present, we have noted that the United States has global deterrence relationships with Russia and China, as well as regional relationships that include (but are not limited to) Russia in the EuroAtlantic and Western Pacific regions, and China in the Western Pacific. Both Russia and China possess non-strategic nuclear-weapon options more specialized to regional deterrence. On the other hand, emerging regional powers with more primitive, lower-yield nuclear weapons create the possibility of self-deterrence by the United States, or reduced responsiveness, created by a deficit of “proportionate” U.S. response options.

The arguments against the development of a low-yield SLBM warhead are easy to anticipate: a "new" military capability, a "more usable” nuclear weapon, lack of a requirement based on current 
relations among the nuclear powers. This last point was anticipated by Colby, with the counter that events could strain the capabilities of a system developed for the Cold War.

Could a low-yield warhead option for Trident II create a box canyon for future development, from which the United States would wish to walk back at some point in the not-so-distant future? The point of course is whether there is a need for a "limited, discriminate, and evidently restrained" option either to manage escalation with a global nuclear power, or to provide a "proportionate" retaliatory response - deterrence by punishment - for an emergent regional nuclear power. In the event that the answer to either is yes, the next question is whether a low-yield warhead delivered by an SLBM, likely the shortest route to developing such a capability, is the preferred option. Beyond the new-capability or usability arguments, we suggest that the desirability of adopting this option hinges on two factors.

First, if deterrence fails, can U.S. decision makers expect that the detonation of a lower-yield SLBM warhead will be recognized as such on the appropriate time scales? We propose that the immediate reaction to any nuclear detonation will be the recognition of massive destruction and the detection of nuclear fallout. With no visual sense of scale for destruction beyond that provided by aging photos of Hiroshima and Nagasaki, the fog of war could well obscure, on times scales appropriate to decision making under fire, the difference between a low-yield W76 and the higheryield options carried by the same missile. The determination of yield could trail by days the decision on response. Thus,

- The availability of the option itself will likely have a useful deterrent effect, especially as a swift-and-sure, proportionate retaliatory response to an emergent regional nuclear power.

- As a responsive, second-use retaliatory option, with some expectation of the scale of a response, the low yield is possibly more likely to be perceived as such.

- Conversely, at the onset of a conflict, at the point at which a pre-emptive low-yield demonstration of resolve is required, whatever the provocation, the low yield is less likely to be recognized on a time scale appropriate to the decision making of the recipient. In other words, the message of "evidently restrained" is much less likely to be received.

Second, how does the ambiguity accompanying the use of an otherwise strategic system - an SLBM - affect its value as an element of extended deterrence? To be sure, TLAM/N, a submarinelaunched cruise missile with greater available yield than the low-yield W76 in question, was judged by U.S. allies to be an acceptable instrument of extended deterrence. Therefore, this question focuses on the expected response to the use of an SLBM.

This last issue is a key one as we look to an uncertain future: are there regional-deterrence situations in which the message sent by the availability of non-strategic options is more appropriate? Alternatively, in the way that basing of non-strategic U.S. weapons in Europe sent, and continues to send, an intended message about U.S. commitment, does U.S. reliance on strategic systems even for extended deterrence send the same message in other regions? Finally, if deterrence fails - a low-probability, high-consequence event - does the availability of only strategic options provide the necessary range of options and flexibility in order to best serve the interests of the United States and its allies?

The future use of LRSO in this role may be more desirable, as suggested by Colby. Heavy bombers are essentially a dual-capable system, even if they are counted - in unique fashion - under New 
START. Nevertheless, the desirability of this option could change dramatically if bombers were one half of a future strategic dyad.

\section{Final Thoughts: Options for the Future}

Before we close, we emphasize three points about the discussion in this section:

- The current path for U.S. nuclear-force development points to a future force qualitatively similar to the force of today: a nuclear triad plus a gravity bomb delivered by T-DCA.

- Although perhaps not ideally suited to all possible anticipated global and regional deterrence situations, the current force is adequate, and foreseeable circumstances do not demand markedly different capabilities.

- Nuclear-force considerations are an element of a broader U.S. national-security policy that supports nonproliferation and arms control by aiming for the reduction of the role for, and the numbers of, nuclear weapons.

This context does not currently call for the development of new nuclear missions or weapons, although modifications that maintain the safety, security, and effectiveness of the existing arsenal are allowed. Nevertheless, we consider the kinds of changes in the security environment alternative futures - that might necessitate the development of new capabilities in the nuclear force.

\section{Evaluating the Circumstances for Deterrence and Use in Case Deterrence Fails}

The point of this section is to consider options that might be needed under future conditions significantly different from those expected today. In the study of Concepts of Analysis for Nuclear Strategy, Daryl Press outlined the three features of such alternative futures most likely to have a top-level effect on nuclear-force requirements: ${ }^{24}$

- The relative conventional military strength of the United States;

- Relations between the major nuclear powers (or Great Powers); and

- The extent of proliferation of nuclear weapons and the strength of the nonproliferation regime.

A significant deterioration of the international situation in one or more of these realms might generate the need for different nuclear-force postures or capabilities.

The purposes to which a nuclear nation would put nuclear weapons, and the types of nuclear weapon, are also a factor in considering the possibility of a change in the nuclear force. As an introduction to a broader subject beyond the scope of this report, we consider the following, somewhat loosely-defined qualitative criteria:

- The circumstances of possible use:

o Offensive (in support of an expansionist objective) vs defensive (in response to an attack) vs non-traditional (the so-called "nuclear car bomb," creating a particularly difficult situation, since response is tied up with the challenging business of attribution of the source).

o In-country by the user of the nuclear weapon (expected to be a defensive use) vs extra-territorially (in which case use could be offensive or defensive).

- The relative characterization of the combatants: 
o Great strategic depth (so-called "big sponge” countries capable of absorbing at least a limited nuclear strike and continuing to function) vs shallow strategic depth (a country for which even a single nuclear strike, or a limited number against a few predominant concentrations of population or industry, would be very difficult to absorb).

o Conventionally-superior militarily vs conventionally-inferior.

- The nature of the weapons:

o High-yield (approaching a hundred kilotons or more) vs low yield (up to about twenty kilotons).

o Strategic systems capable of delivery from intercontinental range (delivered by an ICBM or SLBM, or perhaps delivered by a heavy bomber, although this latter is more ambiguously "strategic") vs non-strategic systems that deliver over shorter range, regional or theater.

o Alternatively, for some nations, strategic systems may be those capable of hitting large-area targets (which some would call counter-value or large-scale counterforce), while non-strategic systems may be those intended for battlefield use.

\section{Considering the Possible Options}

\section{$\underline{\text { Strategic Deterrence }}$}

The core of U.S. strategic deterrence remains the nuclear triad. A 2009 analysis of current and projected versions of the triad, as well as a comparison of the triad to an SSBN/SLBM-only monad or all possible dyads (SSBN/SLBM + ICBMs, SSBN/SLBM + bombers, ICBMs + bombers) can be found in the article by Johnson, Bowie, and Haffa. ${ }^{25}$

Single-warhead ICBMs and the reduced number of missiles projected for the successor to the Ohio-class SSBNs provide for easier downward scaling if desired, offer some upload potential if circumstances dictate, and have some of the key attributes of a more stable nuclear force called for by the 1983 President's Commission on Strategic Forces. ${ }^{26}$

Two options under consideration for a future Ground-Based Strategic Deterrent - mobility and adaptability to carry trajectory-shaping or trajectory-correcting vehicles - could address two challenges confronting ICBMs: increased survivability and the issue of ICBM-launched warheads overflying Russia to reach non-Russian targets of potential interest.

\section{Regional Deterrence}

Regional deterrence, on the other hand, is becoming a more complex problem. The associated issues in an age of emerging nuclear states or global nuclear powers with far less limited objectives than world domination are more complex than those of Cold-War strategic deterrence. Of course, Cold War deterrence involved subtleties appropriate to the age: we recall Garthoff's observation that the number of warheads on U.S. INF-range missile systems was less than the number on similar Soviet systems in order to signal that escalation to the global level was still possible. ${ }^{27}$ Consider as examples the following three deterrence situations that United States decision makers could face in possible alternative futures:

- In-country, defensive use of nuclear weapons by an adversary. Imagine that a nucleararmed adversary badly miscalculates and attacks a U.S. ally, and the United States 
responds with superior conventional force. Imagine also that in the face of a perceived threat to regime survival, this nuclear-armed adversary considers the in-country, defensive use of nuclear weapons against U.S. and allied forces. If the international community perceives that the threat of such use alone inhibits U.S. actions, this could constitute an insult to the nonproliferation regime. We are reminded of the comparisons of Ghaddafi's Libya to Kim's North Korea (which are typically made without consideration of the relative sizes of the two nations' militaries, the vastly different terrain in each country, and the conventional artillery threat to South Korea's capital). Even worse, if actual nuclear use by an adversary blunted a U.S. and allied assault, making it in some sense "successful," the damage to the nonproliferation regime is enormous.

- $\quad$ Reassurance of U.S. allies with limited strategic depth threatened by an emergent nuclear power. An extreme example of the former would be Israel or the Gulf States under the threat of a nuclear Iran. Less extreme is South Korea, with the concentration of population and government within conventional artillery range of the demilitarized zone, or Japan, with the high concentration of population and industry near Tokyo and Osaka. For Japan, this factor was recognized in Japanese analyses of its security situation. ${ }^{28,29}$ Reassurance of such allies depends on the maintenance of a swift and sure retaliatory capability. However, the threat of retaliation must be backed with not only the resolve to employ it in the defense of U.S. allies, but also defensive capabilities and very clear messaging and responsive capability in the event that an attack seems imminent. Simultaneous reassurance and deterrence presents special challenges. ${ }^{\dagger}$

- $\quad$ Extraterritorial, non-strategic, offensive use of nuclear weapons in support of limited military objectives against a U.S. ally. The United States has Cold War-era experience in deterring large-scale conflict with an implacable, ideologically-opposed enemy backed by strategic nuclear capability. The demise of the Soviet Union has lowered the geopolitical and military stakes dramatically. However, in an alternate future in which relations with Russia declined precipitously (for reasons one cannot foresee today), one could imagine that limited military actions on the Russian periphery would be supported by the implicit threat of non-strategic nuclear weapons. Indeed, positioning and posturing such weapons to manipulate periphery states by the threat alone would constitute a threat to regional stability.

Before we consider the options for facing threats such as these, we offer two observations about the future of regional deterrence. First, we address a commonly asked question: Can conventional weapons replace nuclear weapons in accomplishing at least some deterrence missions? ${ }^{30}$ Our reply is that the United States has been making these kinds of replacements continuously, during and after the Cold War. Since the high point of U.S. nuclear war planning during the Cold War, the United States has eliminated all of its non-strategic naval and ground-launched nuclear weapons, its nuclear artillery, land mines, and ballistic missile defense system, and its air-to-air missiles. Nevertheless, the 2010 Nuclear Posture Review Report pointed to a more focused role for the remaining U.S. nuclear weapons: "The fundamental role of U.S. nuclear weapons ... is to deter nuclear attack on the United States, our allies, and partners.” That formulation - "fundamental role" - is to be distinguished from the more restrictive role that did not make it into the Review, "sole purpose," a point discussed in a recent paper by Brad Roberts, former Deputy Assistant

Indeed, allies as well as adversaries apply a worst-case analysis to their security situation, which causes allies to minimize the capability meant to assure them, while adversaries magnify the same capability, a situation meant to be moderated through regular consultation with the recipients of extended deterrence. 
Secretary of Defense for Nuclear and Missile Defense Policy. ${ }^{31}$ In this spirit, U.S. non-strategic weapons should exist for the primary, but not necessarily sole, purpose of deterring the use of nuclear weapons, or other weapons of mass destruction, by our adversaries. That includes first use as well as further use; i.e., subsequent use after the initiation of nuclear conflict, a situation perhaps more accurately characterized as escalation control, a subject beyond our scope here.

Our second observation is that, in thinking of possible alternative futures, planners must structure a nuclear force for strategic stability, as well as regional nuclear deterrence if possible, and escalation control if necessary. This brings to mind three points:

- Schelling's description of deterrence in terms of "the exploitation of potential force."

- Colby's admonition that making prevention of nuclear use the only goal creates its own vulnerability.

- Kenneth Waltz' comment: “If countries armed with nuclear weapons go to war, they do so knowing that their suffering may be unlimited. ... In a conventional world, one is uncertain about winning or losing. In a nuclear world, one is uncertain about surviving or being annihilated."32

In this vein, we compare the wide diversity of Russia's non-strategic nuclear force to the limited non-strategic options available to the United States. Russia admits to its current conventional inferiority to NATO. Further, given Russia's long borders and lack of offensive conventional strength, those non-strategic nuclear forces are less threatening in providing a range of last-resort defensive options than they would be if Russia were an offensive threat with superior conventional capability. On the other hand, in view of the conventional superiority of the U.S. military, a similar non-strategic U.S. nuclear arsenal would be far more threatening; however, the United States must have sufficient capability to deter offensive non-strategic nuclear use and control nuclear escalation if first use occurs.

The challenge of deterring regional nuclear threats could be addressed in part by the following adaptations of existing strategic systems:

- A low-yield SLBM warhead, as discussed by Colby. This offers (1) reliable defense penetration, (2) rapid retaliatory response, and (3) a proportionate response against new nuclear powers not yet possessing high-yield weapons of their own - provided the lowyield option on an otherwise high-yield system is discerned. A swift and sure retaliatory capability is particularly valuable in deterring regional adversaries and reassuring allies with limited strategic depth. In response to the possible counter argument that a low-yield system is more "usable," we argue that the possibility of U.S. self-deterrence due to an unwillingness to respond at the substantially higher yield of current SLBM warheads actually makes deterrence less effective, increasing the possibility for nuclear use by an adversary.

- A limited strike with ALCM or LRSO in the future, this latter mentioned by Colby also as a possibly more desirable option than the low-yield SLBM. Presumably these weapons can offer a proportionate response, and they have pinpoint accuracy; however, defense penetration is more challenging for a cruise missile, and response is slowed by the longer flight times (hours as opposed to tens of minutes). With regard to the longer flight time, a heavy bomber with a full load of cruise missiles on the loose is a very flexible option for the user that nevertheless offers a very sobering prospect for the adversary until it becomes clear how many of those cruise missiles are going to be released. 
The common disadvantage of these systems is the uncertain message sent by the low-yield employment of a strategic weapon also capable of operation in a high-yield mode. The two immediate observables following a nuclear detonation are the enormous destruction and the accompanying radiation. Although the destruction at high yields could be orders of magnitude larger than that of the low-yield option, few eyes are calibrated to quickly detect the difference. Careful analysis would "prove" the difference, but in the political atmosphere surrounding nuclear conflict, "proof" is heavily influenced by the desired conclusion of the parties involved.

For similar reasons, and because of the increased confusion in wartime that Colby acknowledges, we are skeptical of the utility of low-yield, discriminate options in a signaling or de-escalatory role. To be sure, one can find substantial support for this nuclear role in the Russian defense-analysis literature, but perhaps the best reason one could find on the U.S. side for developing such an option would be the possibility of deterring or limiting its use by an adversary.

The remaining option now available is nuclear-armed heavy bombers or T-DCA armed with B61 gravity bombs. This latter option is an element of the glue holding NATO together as a nuclear alliance. This option requires in-theater storage of nuclear weapons, either permanently - the current case in Europe - or temporarily. Further, armed with B61s, T-DCA are required to penetrate an integrated air-defense system basically to within visual range of the target, drop their ordnance, and then fly back to friendly territory.

Looking forward, if regional or global security were to deteriorate to the point that another, or better, regional nuclear deterrent capability were required, it seems that either some kind of shortrange standoff missile for T-DCA or a resurrected submarine-launched cruise missile are likely options. As we discuss in the Appendix, there are multiple options for a short-range standoff missile (our aforementioned N-SRSO). Basically, the end points for N-SRSO technology are speed - either supersonic or hypersonic - and stealth, with the optimal solution likely somewhere in between. As we showed earlier in Table 1, the long-retired SRAM II - an example of a supersonic rocket - was quite similar in size to the B61, although given the high density of the rocket propellant, it was almost three times the weight. As discussed in the Appendix, the negative for hypersonic systems, which use air-breathing "scramjet" engines, is the large size that accompanies both the rocket booster they require to reach the speeds necessary for the scramjet engine to operate and the fuel they must carry (at much lower density, and thus higher volume, than solid rocket propellant). Stealth, however, as discussed by Letsinger, may be an asset of diminishing value, unless combined with at least supersonic speed, due to improvements in radar systems and processing directed against it. ${ }^{33}$

Finally, we consider the resurrection of submarine-launched cruise missiles such as TLAM/N. To return to our earlier discussion, they offer in-theater basing without the challenges of foreign basing; however, on a submarine, they offer little in the way of visible strategic message once the submarine is deployed. Potentially, submarine basing in-theater shortens the response time relative to ALCM or LRSO on bombers based in the United States, and it offers substantial advantage in weapons security over temporary T-DCA basing. The nuclear explosive is essentially that provided by ALCM or LRSO, though, so there is little or no functional advantage there. Thus, it appears that a new submarine-launched cruise missile would offer advantages in potentially improved nonstrategic response time and weapon security, but the disadvantages of little visible strategic messaging and the growing danger of exposure of the submarine's location when it launches. 


\section{Appendix: Options for Future Regional Nuclear Deterrent Capabilities}

Possible future options for a range of nuclear deterrent capabilities - strategic and regional - can be divided first into those that are modifications of strategic nuclear-weapon systems and those that would be non-strategic nuclear weapons. In the former class, for regional application, we discussed a low-yield SLBM warhead option and use of an air-launched cruise missile - ALCM today, LRSO in the future. In addition, it is possible that options considered for delivery by surface-launched missile boosters for Conventional Prompt Global Strike might be adapted for use in either a strategic or regional nuclear deterrent role. ${ }^{34}$

The Defense Advanced Research Projects Agency (DARPA) and the U.S. Army have both tested unpowered hypersonic boost-glide vehicles. The concept involves the use of a surface-launched missile to boost a hypersonic glide vehicle to an elevation above the atmosphere, from which it reenters the atmosphere at high velocity and performs non-ballistic maneuvers to achieve cross range and glide range well beyond the capacities of ballistic reentry vehicles. The missile can be either an ICBM or SLBM devoted to non-nuclear weapon delivery to strategic ranges.

- DARPA's project was the more ambitious; as part of its FALCON program (Force Application and Launch from Continental United States), two flight tests of the Hypersonic Test Vehicle (HTV-2) were conducted in 2010 and 2011. According to DARPA, the second flight test demonstrated "stable aerodynamically controlled flight" at speeds up to Mach 20. Flight was terminated due to unexpectedly rapid degradation of the flight surfaces. ${ }^{35}$ A third flight test was cancelled as DARPA shifted its focus from strategic hypersonic applications to tactical hypersonic missions. ${ }^{36}$

- The U.S. Army's Advanced Hypersonic Weapon (AHW) ${ }^{37}$ employs the Sandia National Laboratory's Sandia Winged Energetic Reentry Vehicle Experiment (SWERVE) reentry technology demonstrator concept. ${ }^{38}$ This concept involves the integration of an unpowered conical aeroshell with strakes and flaperons used to alter the direction of flight and impose and maintain an aerodynamic angle-of-attack to generate lift. The AHW achieves hypersonic speeds via a large missile booster (ICBM or SLBM class) and uses active controls to perform reentry maneuvers and glide to the target, depositing kinetic energy onto its target. In a 2011 test flight, an AHW missile/maneuvering-vehicle system employing a three-stage booster successfully flew 2,000 kilometers from Kauai to Kwajalein. However, an AHW does not possess nearly the aerodynamic efficiency of an HTV-2, starkly reducing its glide and cross range capacity versus HTV-2.

Despite the intricate shapes of aerodynamic vehicles like the HTV-2, their lack of propulsion prevents them from matching the cross range or glide range of hypersonic scramjet systems exemplified by the X-43 or X-51A. ${ }^{39}$ Delivery vehicles with propulsion systems that do not carry their own oxidizer are known as "airbreathers.” They operate at extreme velocity and have large cross- and glide-range capacity versus a ballistic RV, due to their ability to maintain velocity while maneuvering. ${ }^{40}$ The X-51A Waverider was flight tested in May 2013. ${ }^{41}$ Released from a B-52 at 50,000 feet and a speed of Mach 0.8, the solid booster of the ATACMS (Army Tactical Missile System) accelerated the X-51A scramjet to Mach 4.9 and an elevation of 63,000 feet. At that point, the booster fell away, and the X-51A flew for an additional 210 seconds, climbing to 64,000 feet and reaching a speed of Mach 5.1, at which point it exhausted its fuel while still accelerating. The 


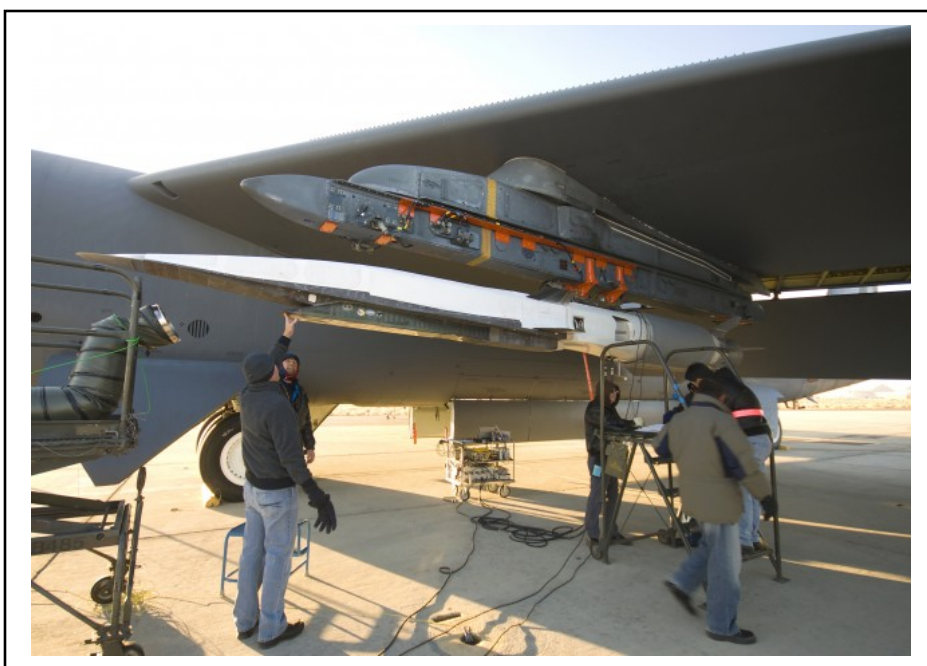

Figure 2. X-51A “stack," under the wing of a B-52. Air Force photo. test system is shown in Figure 2. The scramjet (white) is forward, extending back to the small wings; aft of that is the inter-stage, followed by the gray ATACMS booster. According to the Air Force, the X-51A has a length of 7.6 meters ( 4.3 meters for the scramjetpowered cruiser on the front end, 1.5 meters for the interstage, and 1.8 meters for the booster), and the mass of the whole system is about 1,820 kilograms. $^{42}$ Its range is specified to be over 720 kilometers, its top speed is Mach 6, and its operating ceiling is over 21,000

meters. The X-51 is intended to provide the basis for development of the High-Speed Strike Weapon (HSSW), which is to be deliverable by the B-2 and F-35.

The obvious intended advantage of the proposed HSSW over the SRAM II, which was cancelled by the first Bush administration, is speed: Mach 6 vs Mach 2+. Additionally, the X-51 range of over 700 kilometers is almost double the expected 400 kilometers of SRAM II. However, an HSSW, with its scramjet, interstage, and rocket booster engine is much more complex, heavier, and longer than the two-pulse solid rocket of the SRAM II. Indeed, while the SRAM II was to have room to carry a nuclear warhead, the X-51 appears to have inadequate room for the explosive.

The alternative to speed for evading defenses is of course stealth. Stealthy cruise missiles, like Boeing's JABMM (Joint Air-Breathing Multi-Role Missile) ${ }^{7}$ or Lockheed's JASSM (Joint Air-toSurface Stand-off Missile), ${ }^{43}$ can ideally reach targets before detection, or delay detection and targeting sufficiently that the defensive systems cannot take out the incoming cruise missile. Stealth becomes important given the rapid advancement of air defense networks when coupled to the cruise missile's moderate speed. Cruise missiles represent the simplest technological option, but like the HSSW and SRAM, a cruise missile requires its carrier to transit to the weapon dispense point. And, the cruise missile flies at less than one-fifth the speed of the attack missile, and less than one-twentieth of the HTV-2.

\section{References}

1 For a discussion of the funding history of the RRW program, see: Jonathan Medalia, The Reliable Replacement Warhead Program: Background and Current Developments, Congressional Research Service, July 27, 2009, doc. no. RL32929, available from http://www.crs.gov.

2 JASON group led by R. J. Hemley and D. Meiron, Pit Lifetime, November 20, 2006, The MITRE Corporation, document no. JSR-06-335.

3 JASON, Reliable Replacement Warhead, Executive Summary, September 7, 2007, The MITRE Corporation, document no. JSR-07-336E. 
4 Report of the Defense Science Board Task Force on Nuclear Capabilities, Report Summary, December 2006, Office of the Undersecretary of Defense for Acquisition, Technology, and Logistics, available from http://www.defense.gov/npr/docs/dsb\%20nuclear\%20capabilities\%20foster\%20welch.pdf

5 Nuclear Weapons Complex Assessment Committee, The United States Nuclear Weapons Program, The Reliable Replacement Warhead, April 2007, the American Association for the Advancement of Science, available from http://www.aaas.org/news/releases/2007/media/rrw_report_2007.pdf

6 Committee on the Evaluation of Quantification of Margins and Uncertainties for Assessing and Certifying the Reliability of the Nuclear Stockpile, National Research Council, Evaluation of Quantification of Margins and Uncertainties for Assessing and Certifying the Reliability of the Nuclear Stockpile, 2008, National Academies Press, available from http://www.nap.edu/catalog/12531.html.

7 William J. Perry and James R. Schlesinger (chairmen), America's Strategic Posture, The Final Report of the Congressional Commission on the Strategic Posture of the United States, 2009, United States Institute of Peace Press, available from http://www.usip.org/programs/initiatives/congressional-commission-thestrategic-posture-the-united-states.

8 Nuclear Weapons Complex Infrastructure Task Force, Secretary of Energy Advisory Board, Recommendations for the Nuclear Weapons Complex of the Future, July 13, 2005, Department of Energy, available from http://www.doeal.gov/SWEIS/DOEDocuments/049\%20SEAB\%202005.pdf

9 Report on the Transformation of the National Nuclear Security Administration Nuclear Weapons Complex, January 31, 2007, Office of Defense Programs, National Nuclear Security Administration, Department of Energy, available from http://nnsa.energy.gov/sites/default/files/nnsa/news/documents/Trans_of_NNSA_WC_2007-31-07.pdf Report of the Defense Science Board Task Force on Nuclear Capabilities, Report Summary, December 2006, p. 39.

11 Jonathan Medalia, The Reliable Replacement Warhead Program: Background and Current Developments, Congressional Research Service, July 27, 2009, p. 11.

12 JASON, Reliable Replacement Warhead, Executive Summary, September 7, 2007, p. 3.

13 Jonathan Medalia, Nuclear Warheads: The Reliable Replacement Warhead Program and the Life Extension Program, Congressional Research Service, updated December 3, 2007, doc. no. RL33748, p. CRS-27, available from http://www.crs.gov.

14 William J. Perry and James R. Schlesinger (chairmen), America's Strategic Posture, The Final Report of the Congressional Commission on the Strategic Posture of the United States, 2009, p. 42.

15 The Nuclear Posture Review Report, April 2010, p. xiv.

16 U.S. Dept. of Energy, Fiscal Year 2014 Stockpile Stewardship and Management Plan, Report to Congress, June 2013, Washington, DC, available from the website of the National Nuclear Security Administration, http://nnsa.energy.gov/sites/default/files/nnsa/06-13-inlinefiles/FY14SSMP_2.pdf.

17 John R. Harvey, “On the Path to a '3+2 Vision' for U.S. Nuclear Forces," presented to the Peter Huessy Breakfast Seminar Series, 13 June 2013, available through the website for the Air Force Association, http://secure.afa.org/HBS/transcripts/2013/June\%2013\%20-\%20Additional\%20Informtion.pdf.

18 GAO, Unclassified Summary of GAO's SRAM II/T Classified Report, enclosure to a GAO memo to Defense Secretary Aspin, 24 February 1992, GAO/NSIAD-92-145R.

19 President George H.W. Bush, Address to the Nation on Reducing United States and Soviet Nuclear Weapons, 27 September 1991, available from the website of the George Bush Presidential Library and Museum, http://bushlibrary.tamu.edu/research/public_papers.php?id=3438\&year=1991\&month=9.

20 Statement by Senator Dianne Feinstein, Hearing to Examine the Proper Size of of the Nuclear Weapons Stockpile to Maintain a Credible U.S. Deterrent, July 25, 2012, Energy and Water Subcommittee of the Senate Appropriations Committee, webcast available from http://www.appropriations.senate.gov/webcasts.cfm?method=webcasts.view\&id=3323b75b-a942-4a0481cf-9fa0bd297564.

21 Elbridge Colby, Defining Strategic Stability: Reconciling Stability and Deterrence, from Strategic Stability: Contending Interpretations, E. A. Colby and M.S. Gerson eds., Strategic Studies Institute and U.S. Army War College Press, Carlisle, PA, February 2013; available from http://www.StrategicStudiesInstitute.army.mil.

22 Helmut Schmidt, 1977 Alastair Buchan Memorial Lecture, October 28, 1977, available in Survival, vol. 20, no. 1, January/February 1978, p. 2. 
23 These doctrinal shifts can be traced through the dropping of Russia's no-first-use pledge in its 1993 Military Doctrine, to then-Minister of Defense Sergey Ivanov's white paper, Urgent Tasks of the Development of the Russian Federation Armed Forces, October 2003, obtained from the website of RIANovosti.

24 Daryl G. Press, Alternative Futures and U.S. Nuclear Force Requirements, from Concepts \& Analysis of Nuclear Strategy, (CANS - Theory Team), Supporting Documents (May 1, 2011)

25 Dana J. Johnson, Christopher J. Bowie, and Robert P. Haffa, Triad, Dyad, Monad? Shaping the U.S. Nuclear Force for the Future, Mitchell Paper 5, Mitchell Institute for Airpower Studies, December 2009, available from http://www.afa.org/mitchell/reports/MP5_Triad_1209.pdf. Report of the President's Commission on Strategic Forces, chaired by Brent Scowcroft, April 1983.

27 R. L. Garthoff, Détente and Confrontation: U.S.-Soviet Relations from Nixon to Reagan, Washington, D.C., Brookings Institution, 1994.

28 Yuri Kase, The Costs and Benefits of Japan's Nuclearization: An Insight into the 1968/70 Internal Report, The Nonproliferation Review/Summer 2001, p. 55.

29 Llewelyn Hughes, Why Japan Will Not Go Nuclear (Yet), International and Domestic Constraints on the Nuclearization of Japan, International Security, vol. 31, no. 4, p. 67 (Spring 2007).

30 See, as one example, Michael S. Gerson, "Conventional Deterrence in the Second Nuclear Age," Parameters, p. 32, Autumn 2009

31 Brad Roberts, "Extended Deterrence and Strategic Stability in Northeast Asia," published on the website of the National Institute of Defense Studies, Japan, 9 Aug 2013, http://www.nids.go.jp/english/publication/visiting/index.html

32 Kenneth Waltz, The Spread of Nuclear Weapons: More May Be Better, Adelphi Papers, Number 171 (London: International Institute for Strategic Studies, 1981).

33 Jonathan M. Letsinger, Hypersonic Global Strike Feasibility and Options, Master's Degree thesis, Air War College, Air University, Montgomery, AL, 15 February 2012.

34 For a new analysis of Conventional Prompt Global Strike options, see: James M. Acton, Silver Bullet? Asking the Right Questions about Conventional Prompt Global Strike, Carnegie Endowment for International Peace, Washington, DC, 2013.

35 DARPA, Engineering Review Board Concludes Review of HTV-2 Second Test Flight, April 20, 2012, available online at http://www.darpa.mil/NewsEvents/Releases/2012/04/20.aspx.

36 Graham Warwick, Darpa Refocuses Hypersonics Research on Tactical Missions, Aviation Week \& Space Technology, July 8, 2013, available online at http://www.aviationweek.com/Article.aspx?id=/articlexml/AW_07_08_2013_p24-593534.xml\&p=1.

37 Jason B. Cutshaw, U.S. Army USASMDC/ARSTRATUS, Army Successfully Launches Advanced Hypersonic Weapon Demonstrator, November 23, 2011, available at http://www.army.mil/article/69855; and Department of Defense, Department of Defense Announces Successful Test of Army Advanced Hypersonic Weapon Concept, available at http://www.defense.gov/releases/release.aspx?releaseid=14920.

38 Heather Clark, Labs Technology Launched in First Test Flight of Army's Conventional Advanced Hypersonic Weapon, Sandia Lab News, May 18, 2012, available online at http://www.sandia.gov/LabNews/120518.html.

39 Boeing Defense, Space and Security, Backgrounder: X-51A WaveRider, September 2012, available at http://www.boeing.com/assets/pdf/defense-space/military/waverider/docs/X-51A_overview.pdf.

40 Richard Mutzman, et.al., Air Force Research Laboratory, X-51 Development: A Chief Engineer's Perspective, 17th AIAA International Space Planes and Hypersonic Systems and Technologies Conference, 13 April 2011, available online at https://www.aiaa.org/uploadedFiles/AboutAIAA/Press_Room/Key_Speeches-Reports-and-Presentations/RMutzman_and_JMurphy_X51_Development_2011.pdf

41 Guy Norris, High-Speed Strike Weapon to Build on X-51 Flight, Aviation Week and Space Technology, May 20, 2013, available online at ttp://www.aviationweek.com/Article.aspx?id=/articlexml/AW_05_2013_p24-579062.xml.

$42 X$-51A WAVERIDER, May 3, 2013, available online from the official website of the U.S. Air Force, http://www.af.mil/information/factsheets/factsheet.asp?fsID=17986.

43 Lockheed-Martin, JASSM ${ }^{\circledR}$ : The Best Value of Any Air-to-Surface Missile in Its Class, 2012, available at http://www.lockheedmartin.com/content/dam/lockheed/data/mfc/pc/jassm/mfc-jassm-pc.pdf. 